\title{
Effectiveness of physical activity on depression, anxiety, stress and quality of life of patients on hemodialysis.
}

\author{
Amirtha Santhi $S^{1 *}$, Rebecca Samson ${ }^{2}$, Srikanth ${ }^{3}$, Pethuru $D^{4}$ \\ ${ }^{1}$ Saveetha University, Chennai, Tamil Nadu, India \\ ${ }^{2}$ College of Nursing, Pondicherry Institute of Medical Sciences, Pondicherry, India \\ ${ }^{3}$ Pondicherry Institute of Medical Sciences, Pondicherry, India \\ ${ }^{4}$ Department of General Practice, Al Nahil International Clinic, Kuwait, India
}

\begin{abstract}
Individuals diagnosed with Chronic Kidney Disease (CKD) usually develop psychiatric complications as the dialysis procedure causes changes in the physical health and social life. Though the literature supports beneficial effects of exercise programmes in dialysis patients, the implementation of exercise as a part of clinical care is very less. Hence, the present study was undertaken to provide further evidence for the effectiveness of physical activity depression, anxiety, stress and quality of life of patients on hemodialysis. A total of 14 patients including males and females who were undergoing hemodialysis at selected hospital and who fulfil the selection criteria were included in the present study. The quality of life of the participants was collected by interview method using modified Kidney Disease Quality of Life (KDQOL) scale and Depression, Anxiety and Stress Scale (DASS 21). In this study regular exercise program has reduced depression, anxiety and stress and improved quality of life in hemodialysis patients. Hence, it is suggested to perform more qualitative and quantitative studies in this area to support adoption of physical exercise in the routine care of hemodialysis patients.
\end{abstract}

Keywords: Depression, Anxiety, Stress, Quality of life, Hemodialysis.

Accepted on March 07, 2018

\section{Introduction}

Individuals diagnosed with Chronic Kidney Disease (CKD) usually develop psychiatric complications as the dialysis procedure causes changes in the physical health and social life [1]. This may further decrease the quality of life. Studies have reported higher levels of depression in patients with chronic kidney diseases [2]. Further, CKD patients with depression are at high risk of frequent hospitalization and death when compared to those without complications [3]. It was reported that dialysis shift may have an impact on sleep disorders, quality of life, and mortality [4-6]. It was reported that all the domains of quality of life was deteriorated in CKD patients. Further, it was suggested that assessment of quality of life in CKD patients is an ideal indicator of the outcome of the intervention [7,8]. Regular practice of physical exercise improves physical and mental health and improves the quality of life [9]. Though the literature supports beneficial effects of exercise programmes in dialysis patients, the implementation of exercise as a part of clinical care is very less. Hence, the present study was undertaken to provide further evidence for the effectiveness of physical activity depression, anxiety, stress and quality of life of patients on hemodialysis.

\section{Materials and Methods}

\section{Participants}

A total of 14 patients including males and females who were undergoing hemodialysis at selected hospital and who fulfil the selection criteria were included in the present study. The participants were selected using simple random technique and Stratified random sampling technique was used to allot the participants into the experimental and control group. The participants who receive hemodialysis on morning hours were allotted to the experimental group $(n=7)$ and participants who receive hemodialysis on afternoon hours were allotted for control group $(\mathrm{n}=7)$.

\section{Inclusion criteria}

Male and female patients with in the age group of 40-65 y, receiving regular hemodialysis for $>2$ times a week and can understand Tamil or English languages were included in the study. 


\section{Exclusion criteria}

Patients diagnosed with hepatitis B, hepatitis C and HIV, those receiving emergency dialysis, with history of uncontrolled hypertension, heart failure, heart block, cardiac arrhythmias, third degree AV heart block, suspected aneurysm and recent significant change in resting ECG and any orthopaedic or musculoskeletal limitations were excluded from the study.

\section{Study design}

After recording the baseline values, the quality of life of the participants were collected by interview method using modified Kidney Disease Quality of Life (KDQOL) scale and Depression, Anxiety and Stress Scale (DASS 21). Then experimental group was involved in 15 minutes of physical activity during hemodialysis for the period of 2 months. Control group received the routine care practiced in the hospital. The routine practice in the hospital is, after starting the hemodialysis the patients were allowed to take rest and no specific physical activity was practiced. At the end of $2^{\text {nd }}$ month the Quality of life of the participants were collected by interview method using modified kidney disease quality of life (KDQOL) scale and Depression, Anxiety and Stress Scale (DASS 21). The $2^{\text {nd }}$ month assessment was taken for post-test.

\section{Study setting}

The present experimental study was conducted in dialysis unit at Pondicherry Institute of Medical Sciences, Pondicherry.

\section{Methods}

Intervention: The study participants were connected to the hemodialysis machine. After $30 \mathrm{~min}$ of hemodialysis the participants were instructed to do the physical activity of the extremities for $15 \mathrm{~min}$ duration. The participants are instructed not to do any activity in the extremity that is connected to the hemodialysis machine. During hemodialysis the physical activity done by the participants were supervised by the staff nurse or the physiotherapist. Vital signs of the participants were monitored during exercise. This physical activity is done by the participants during hemodialysis for the period of 2 months. The physical activity includes elbow flexion/ extension, forearm supination/pronation, wrist circumduction, fingers flexion/extension, ankle rotation, toes flexion, extension and hyper extension.

\section{Statistical analysis}

The paired ' $t$ ' test is used to compare the pre-test and post-test level of biochemical values in experimental group.

\section{Ethical consideration}

The present study was approved by Institutional Human Ethical Committee of Saveetha University, Chennai (020/08/2016/IEC/SU Dated $11^{\text {th }}$ August 2016) and Institutional Review Board, Pondicherry Institute of Medical Sciences, Pondicherry.

\section{Results}

Table 1 shows the pre-test kidney disease quality of life in experimental and control group. Both the groups are comparable as there is no significant difference in the $\mathrm{p}$ values. Table 2 shows the comparison of pre-test and post-test kidney disease quality of life scores in experimental group. There is a significant difference $(\mathrm{p}=0.008)$ between the pre-test and posttest symptoms of patients in the experimental group. But there is no significant difference in the general health, physical activity, social activity, pain, effect of kidney disease, sexual function, sleep, social support and patient satisfaction. The paired ' $t$ ' test is used to compare the pre-test and post-test quality of life scores. Table 3 shows the comparison of pre-test and post-test kidney disease quality of life scores in control group. There is no significant difference in the general health, physical activity, social activity, pain, symptoms, effect of kidney disease, sexual function, sleep, social support and patient satisfaction. The paired ' $t$ ' test is used to compare the pre-test and post-test quality of life scores. Table 4 shows the distribution of pre-test and post-test Depression, Anxiety and Stress score Levels in experimental and control group. In pretest depression $42.9 \%$ of the participants do not have depression and $42.9 \%$ had moderate depression in experimental group. In post-test $57.1 \%$ participants do not have depression. In pre-test anxiety $14.3 \%$ had moderate anxiety. But no one had moderate anxiety in post-test in experimental group. According to stress score $28.6 \%$ had moderate stress in pre-test, but in post-test no one had moderate stress. In control group $42.9 \%$ participants had mild and $42.9 \%$ had moderate depression. In anxiety $85.7 \%$ do not have anxiety and $14.2 \%$ had moderate anxiety. There is no change in the post test depression and anxiety score in control group. In stress score $71.4 \%$ do not have stress in pre-test but in post-test only $57.1 \%$ participants do not have stress. Table 5 shows the comparison of pre-test and post-test DASS levels in experimental group. There is no significant difference between the pre-test and post-test level of depression, anxiety and stress. Chi square test is used to compare the pre-test and post-test DASS levels. Table 6 shows the comparison of pre-test and post-test DASS levels in control group. There is no significant difference between the pre-test and post-test level of depression, anxiety and stress. Chi square test is used to compare the pre-test and post-test DASS levels. Table 7 shows the comparison of posttest kidney disease quality of life score in experimental and control group. There is no significant difference in the general health, physical activity, social activity, pain, symptoms, effect of kidney disease, sexual function, sleep, social support and patient satisfaction. The unpaired ' $t$ ' test is used to compare the pre-test and post-test kidney disease quality of life scores. Table 8 shows the comparison of post-test DASS levels in experimental and control group. There is no significant difference in the post test levels of depression, anxiety and stress between experimental and control group. The chi square 
Effectiveness of physical activity on depression, anxiety, stress and quality of life of patients on hemodialysis

test is used to compare the post-test DASS levels between experimental and control group.

Table 1. Distribution of pre-test kidney disease quality of life in experimental and control group $(n=14)$.

\begin{tabular}{lllll}
\hline S no. & Quality of life scale & $\begin{array}{l}\text { Experimental } \\
\text { group }(\mathbf{n = 7})\end{array}$ & $\begin{array}{l}\text { Control } \\
(\mathbf{n}=7)\end{array}$ & group \\
\hline 1 & General health & $48.21 \pm 13.36$ & $46.43 \pm 11.89$ & 0.79 \\
\hline 2 & Physical activity & $57.94 \pm 24.81$ & $57.94 \pm 16.93$ & 1 \\
\hline 3 & Social activity & $82.14 \pm 31.34$ & $78.57 \pm 17.25$ & 0.79 \\
\hline 4 & Pain & $57.50 \pm 29.55$ & $63.57 \pm 14.57$ & 0.63 \\
\hline 5 & Symptoms & $83.30 \pm 9.92$ & $83.33 \pm 7.60$ & 1 \\
\hline 6 & Effect of kidney disease & $78.57 \pm 8.01$ & $76.43 \pm 8.52$ & 0.63 \\
\hline 7 & Sexual function & $81.25 \pm 8.83$ & $91.67 \pm 7.22$ & 0.13 \\
\hline 8 & Sleep & $64.64 \pm 17.76$ & $71.43 \pm 15.54$ & 0.46 \\
\hline 9 & Social support & $97.61 \pm 6.31$ & $95.22 \pm 8.14$ & 0.55 \\
\hline 10 & Patient satisfaction & $89.29 \pm 13.36$ & $89.29 \pm 13.36$ & 1 \\
\hline
\end{tabular}

Table 2. Comparison of pre-test and post-test kidney disease quality of life scores in experimental group $(n=7)$.

\begin{tabular}{|c|c|c|c|c|c|c|}
\hline S no. & Quality of life scale & Pre test & & Post test & $\begin{array}{l}\text { 't' } \\
\text { value }\end{array}$ & $\mathbf{p}$ \\
\hline 1 & General health & $\begin{array}{l}48.21 \\
13.36\end{array}$ & \pm & $\begin{array}{l}51.79 \\
11.36\end{array}$ & \pm 1.549 & 0.172 \\
\hline 2 & Physical activity & $\begin{array}{l}57.94 \\
24.81\end{array}$ & \pm & $\begin{array}{l}59.52 \\
21.921\end{array}$ & \pm 1 & 0.356 \\
\hline 3 & Social activity & $\begin{array}{l}82.14 \\
31.34\end{array}$ & \pm & $\begin{array}{l}82.14 \\
31.34\end{array}$ & \pm & - \\
\hline 4 & Pain & $\begin{array}{l}57.50 \\
29.55\end{array}$ & \pm & $\begin{array}{l}62.14 \\
24.34\end{array}$ & \pm 1.41 & 0.208 \\
\hline 5 & Symptoms & $83.30 \pm 9.92$ & & $\begin{array}{l}86.31 \\
10.13\end{array}$ & \pm 3.873 & $0.008^{*}$ \\
\hline 6 & $\begin{array}{l}\text { Effect of kidney } \\
\text { disease }\end{array}$ & $78.57 \pm 8.01$ & & $78.57 \pm 8.01$ & - & - \\
\hline 7 & Sexual function & $81.25 \pm 8.83$ & & $81.25 \pm 8.83$ & - & - \\
\hline 8 & Sleep & $\begin{array}{l}64.64 \\
17.76\end{array}$ & \pm & $\begin{array}{l}66.07 \\
16.26\end{array}$ & $\pm \quad 1.549$ & 0.172 \\
\hline 9 & Social support & $97.61 \pm 6.31$ & & $97.61 \pm 6.31$ & - & - \\
\hline 10 & Patient satisfaction & $\begin{array}{l}89.29 \\
13.36\end{array}$ & \pm & $\begin{array}{l}92.86 \\
12.20\end{array}$ & \pm & 0.356 \\
\hline
\end{tabular}

Table 3. Comparison of pre-test and post-test kidney disease quality of life scores in control group $(n=7)$.

\begin{tabular}{|c|c|c|c|c|c|}
\hline S no. & Quality of life scale & pre test & post test & 't' value & p \\
\hline 1 & General health & $46.43 \pm 11.89$ & $\begin{array}{l}44.64 \\
12.20\end{array}$ & 1 & 0.356 \\
\hline
\end{tabular}

\begin{tabular}{lllllll}
\hline 2 & Physical activity & $57.94 \pm 16.93$ & $\begin{array}{l}58.73 \\
15.66\end{array}$ & \pm 1 & 0.356 \\
\hline 3 & Social activity & $78.57 \pm 17.25$ & $\begin{array}{l}78.57 \\
17.25\end{array}$ & \pm & - \\
\hline 4 & Pain & $63.57 \pm 14.57$ & $\begin{array}{l}60.36 \\
12.70\end{array}$ & \pm & 1.536 & 0.175 \\
\hline 5 & Symptoms & $83.33 \pm 7.60$ & $82.14 \pm 6.23$ & 1 & 0.356 \\
\hline 6 & $\begin{array}{l}\text { Effect of } \\
\text { disease }\end{array}$ & kidney & $76.43 \pm 8.52$ & $75.00 \pm 8.66$ & 1 & 0.356 \\
\hline 7 & Sexual function & $91.67 \pm 7.22$ & $91.67 \pm 7.22$ & - & - \\
\hline 8 & Sleep & $71.43 \pm 15.54$ & $\begin{array}{l}73.21 \\
13.21\end{array}$ & \pm & 0.956 & 0.376 \\
\hline 9 & Social support & $95.22 \pm 8.14$ & $95.22 \pm 8.14$ & - & - \\
\hline 10 & Patient satisfaction & $89.29 \pm 13.36$ & $\begin{array}{l}85.71 \\
13.36\end{array}$ & \pm & 0.356 \\
\hline
\end{tabular}

Table 4. Distribution of pre-test and post-test DASS levels in experimental and control group $(n=14)$.

\begin{tabular}{|c|c|c|c|c|c|}
\hline \multirow{3}{*}{ S no. } & \multirow{3}{*}{ DASS levels } & \multicolumn{2}{|c|}{ Experimental group $(n=7)$} & \multicolumn{2}{|c|}{ Control group $(n=7)$} \\
\hline & & Pre-test & Post-test & Pre-test & Post-test \\
\hline & & $f(\%)$ & $f(\%)$ & $f(\%)$ & $f(\%)$ \\
\hline \multirow{4}{*}{1} & Depression & & & & \\
\hline & a) Normal & $3(42.9)$ & $4(57.1)$ & $1(14.2)$ & $1(14.2)$ \\
\hline & b) Mild & $1(14.2)$ & $1(14.3)$ & $3(42.9)$ & $3(42.9)$ \\
\hline & c) Moderate & $3(42.9)$ & $2(28.6)$ & $3(42.9)$ & $3(42.9)$ \\
\hline \multirow{4}{*}{2} & Anxiety & & & & \\
\hline & a) Normal & $5(71.4)$ & $5(71.4)$ & $6(85.7)$ & $6(85.7)$ \\
\hline & b) Mild & $1(14.3)$ & $2(28.6)$ & 0 & 0 \\
\hline & c) Moderate & $1(14.3)$ & 0 & $1(14.3)$ & $1(14.2)$ \\
\hline \multirow{4}{*}{3} & Stress & & & & \\
\hline & a) Normal & $4(57.1)$ & $5(71.4)$ & $5(71.4)$ & $4(57.1)$ \\
\hline & b) Mild & $1(14.3)$ & $2(28.6)$ & $1(14.3)$ & $2(28.6)$ \\
\hline & c) Moderate & $2(28.6)$ & 0 & $1(14.3)$ & $1(14.2)$ \\
\hline
\end{tabular}

Table 5. Comparison of pre-test and post-test DASS levels in experimental group $(n=7)$.

\begin{tabular}{|c|c|c|c|c|c|}
\hline \multirow{2}{*}{ S no. } & \multirow{2}{*}{ DASS levels } & Pre-test & Post-test & \multirow{2}{*}{ 'Chi square } & \multirow{2}{*}{$\mathrm{p}$} \\
\hline & & $f(\%)$ & $f(\%)$ & & \\
\hline \multirow{4}{*}{1} & Depression & & & & \\
\hline & a) Normal & $3(42.9)$ & $4(57.1)$ & \multirow{3}{*}{0.343} & \multirow{3}{*}{0.842} \\
\hline & b) Mild & $1(14.2)$ & $1(14.3)$ & & \\
\hline & c) Moderate & $3(42.9)$ & 2 (28.6) & & \\
\hline \multirow{2}{*}{2} & Anxiety & & & & \\
\hline & a) Normal & $5(71.4)$ & $5(71.4)$ & 1.333 & 0.513 \\
\hline
\end{tabular}




\begin{tabular}{lll}
\hline b) Mild & $1(14.3)$ & $2(28.6)$ \\
\hline c) Moderate & $1(14.3)$ & 0
\end{tabular}

Stress

3

\begin{tabular}{lll}
\hline a) Normal & $4(57.1)$ & $5(71.4)$ \\
\cline { 1 - 2 } b) Mild & $1(14.3)$ & $2(28.6)$ \\
\cline { 1 - 2 } c) Moderate & $2(28.6)$ & 0
\end{tabular}

Table 6. Comparison of pre-test and post-test DASS levels in control group $(n=7)$.

\begin{tabular}{|c|c|c|c|c|c|c|}
\hline \multirow{2}{*}{ S no. } & \multirow{2}{*}{\multicolumn{2}{|c|}{ DASS levels }} & Pre-test & Post-test & \multirow{2}{*}{$\begin{array}{l}\text { Chi } \\
\text { square }\end{array}$} & \multirow{2}{*}{ p } \\
\hline & & & $f(\%)$ & $f(\%)$ & & \\
\hline \multirow{4}{*}{1} & \multicolumn{4}{|c|}{ Depression } & & \\
\hline & a) & Normal & $1(14.2)$ & $1(14.2)$ & & \\
\hline & b) & Mild & $3(42.9)$ & $3(42.9)$ & 0 & 1 \\
\hline & c) & Moderate & $3(42.9)$ & $3(42.9)$ & & \\
\hline \multirow{4}{*}{2} & \multicolumn{4}{|c|}{ Anxiety } & & \\
\hline & a) $\mathrm{N}$ & rmal & $6(85.7)$ & $6(85.7)$ & & \\
\hline & b) $\mathrm{N}$ & & 0 & 0 & 0 & 1 \\
\hline & c) $\mathrm{N}$ & derate & $1(14.3)$ & $1(14.3)$ & & \\
\hline \multirow{4}{*}{3} & \multicolumn{4}{|c|}{ Stress } & & \\
\hline & \multicolumn{2}{|c|}{ a) Normal } & $5(71.4)$ & $4(57.1)$ & & \\
\hline & \multicolumn{2}{|c|}{ b) Mild } & $1(14.3)$ & $2(28.6)$ & 0.444 & 0.801 \\
\hline & \multicolumn{2}{|c|}{ c) Moderate } & $1(14.3)$ & $1(14.3)$ & & \\
\hline
\end{tabular}

Table 7. Comparison of post-test kidney disease quality of life score in experimental and control group $(n=14)$.

\begin{tabular}{|c|c|c|c|c|c|}
\hline S no. & $\begin{array}{l}\text { Kidney disease } \\
\text { quality of life scale }\end{array}$ & $\begin{array}{l}\text { Experimenta } \\
\text { I group }(n=7)\end{array}$ & $\begin{array}{l}\text { Control } \\
\text { group } \\
(n=7)\end{array}$ & 't' value & p \\
\hline 1 & General Health & 51.79 & 44.64 & 1.297 & 0.277 \\
\hline 2 & Physical activity & 59.52 & 58.73 & 0.006 & 0.939 \\
\hline 3 & Social activity & 82.14 & 78.57 & 0.07 & 0.796 \\
\hline 4 & Pain & 62.14 & 60.36 & 0.03 & 0.866 \\
\hline 5 & Symptoms & 86.31 & 82.14 & 0.86 & 0.372 \\
\hline 6 & $\begin{array}{l}\text { Effect of kidney } \\
\text { disease }\end{array}$ & 78.57 & 75 & 0.641 & 0.439 \\
\hline 7 & Sexual function & 81.25 & 91.67 & 2.143 & 0.239 \\
\hline 8 & Sleep & 66.07 & 73.21 & 0.814 & 0.385 \\
\hline 9 & Social support & 97.61 & 95.22 & 0.375 & 0.552 \\
\hline 10 & Patient satisfaction & 92.86 & 85.71 & 1.091 & 0.317 \\
\hline
\end{tabular}

Table 8. Comparison of post-test DASS levels in experimental and control group $(n=14)$.

\begin{tabular}{|c|c|c|c|c|c|}
\hline \multirow[t]{2}{*}{ S no. } & \multirow[t]{2}{*}{ DASS levels } & $\begin{array}{l}\text { Exp. group } \\
(n=7)\end{array}$ & $\begin{array}{l}\text { Control } \\
\text { group }(n=7)\end{array}$ & \multirow[t]{2}{*}{ Chi square } & \multirow[t]{2}{*}{ p } \\
\hline & & $f(\%)$ & $f(\%)$ & & \\
\hline \multirow{4}{*}{1} & Depression & & & & \\
\hline & a) Normal & $4(57.1)$ & $1(14.2)$ & & \\
\hline & b) Mild & $1(14.3)$ & $3(42.9)$ & 3 & 0.223 \\
\hline & c) Moderate & 2 (28.6) & $3(42.9)$ & & \\
\hline \multirow{4}{*}{2} & Anxiety & & & & \\
\hline & a) Normal & $5(71.4)$ & $6(85.7)$ & & \\
\hline & b) Mild & $2(28.6)$ & $0(0.0)$ & 0.309 & 0.213 \\
\hline & c) Moderate & $0(0.0)$ & $1(14.3)$ & & \\
\hline \multirow{4}{*}{3} & Stress & & & & \\
\hline & a) Normal & $5(71.4)$ & $4(57.1)$ & & \\
\hline & b) Mild & $2(28.6)$ & $2(28.6)$ & 1.111 & 0.574 \\
\hline & c) Moderate & $0(0.0)$ & $1(14.3)$ & & \\
\hline
\end{tabular}

\section{Discussion}

Higher depression levels are reported in the patients with CKD [10-15]. Depression and anxiety decreases the quality of life and increases morbidity and mortality in CKD patients [16-18]. Further the CKD was associated with oxidative stress and inflammation of the systems and leads to cardiovascular diseases [11]. Hence, there is a need for the therapies that minimize stress and prevent the cardiovascular complications. Physical exercise is one among the non-pharmacological methods which is beneficial in reducing the stress and anxiety and prevents the depression [12]. Practicing physical exercise in routine day life style improves physical capacity, strength of muscles, cardiovascular function, and improves quality of life [13-15]. In the current study we have observed decrease in the depression, anxiety and stress levels and increased quality of life followed by the regular physical exercise. Our results are in accordance with earlier studies reported beneficial effects of physical exercise on improving both physical and psychological states and overall improvement in quality of life [17-20]. Milani et al. also reported the efficacy of exercise on major depression in heart failure patients, which are consistent with the results of this study $[21,22]$. However, certain studies demonstrated that exercise and physical activity have no effect on depression in hemodialysis patients [23]. Physical exercise program improves muscle power, flexibility of joints, decreases musculoskeletal pain, improves appetite and nutrition quality, self-care ability, getting well sleep and rest, and reducing fatigue for hemodialysis patients. All these beneficial effects allow the CKD patients on hemodialysis to be independent in their regular life so that they can perform their daily activities more effectively. Regular physical exercise prevents depression by increasing blood supply and neurogenesis in brain hippocampus, which acts like antidepressant agents [24]. Structured physical exercise programme during hemodialysis improves physical function 
and quality of life significantly and can be integrated into a hemodialysis routine with a high long-term adherence $[25,26]$. Release of beta-endorphin during the physical exercise plays an important role in construction of hippocampal neurons and reduces depression [27,28]. Physical exercise may also reduce depression by changing the growth and cortisol hormones [29]. Physical activity increases patient's physical and mental fitness and promotes their longstanding self-sufficiency and independence from helping others. In addition it reduces the financial costs of nursing care [30]. All these effects of physical exercise contribute in the increase of quality of life.

\section{Conclusion}

In this study regular exercise program has reduced depression, anxiety and stress and improved quality of life in hemodialysis patients. Hence, it is suggested to perform more qualitative and quantitative studies in this area to support adoption of physical exercise in the routine care of hemodialysis patients.

\section{Conflicts of Interest}

None.

\section{References}

1. Kessler RC, Berglund P, Demler O, Jin R, Koretz D, Merikangas KR. The epidemiology of major depressive disorder: results from the National Comorbidity Survey Replication (NCS-R). JAMA 2003; 289: 3095-3105.

2. Jiang W, Alexander J, Christopher E, Kuchibhatla M, Gaulden LH, Cuffe MS. Relationship of depression to increased risk of mortality and rehospitalization in patients with congestive heart failure. Arch Intern Med 2001; 161: 1849-1856.

3. Hedayati SS, Grambow SC, Szczech LA, Stechuchak KM, Allen AS, Bosworth HB. Physician-diagnosed depression as a correlate of hospitalizations in patients receiving longterm hemodialysis. Am J Kidney Dis 2005; 46: 642-649.

4. Merlino G, Piani A, Dolso P, Adorati M, Cancelli I, Valente M. Sleep disorders in patients with end-stage renal disease undergoing dialysis therapy. Nephrol Dial Transplant 2006; 21: 184-190.

5. Cengić B, Resić H, Spasovski G, Avdić E, Alajbegović A. Quality of sleep in patients undergoing hemodialysis. Int Urol Nephrol 2012; 44: 557-567.

6. Abbott KC, Reynolds JC, Trespalacios FC, Cruess D, Agodoa LY. Survival by time of day of hemodialysis: analysis of United States Renal Data System Dialysis Morbidity and Mortality Waves III/IV. Am J Kidney Dis 2003; 41: 796-806.

7. Unruh ML, Hess R. Assessment of health-related quality of life among patients with chronic kidney disease. Adv Chronic Kidney Dis 2007; 14: 345-352.

8. Kaufman SE. The increasing importance of quality of life research. Clin Res 2001; 1: 18-22.
9. Henson A, Gillespie B, McCarthy A, Finch L, Chatterton S, Devlin J, Hawley C, Orazio L. Intradialytic exercise: A feasibility study. Ren Soc Aust J 2010; 6: 11-15.

10. Hmwe NT, Subramanian P, Tan LP, Chong WK. The effects of acupressure on depression, anxiety and stress in patients with hemodialysis: A randomized controlled trial. Int J Nur Stud 2015; 52: 509-518.

11. Vaziri ND. Gut microbial translocation in the pathogenesis of systemic inflammation in patients with end-stage renal disease. Dig Dis Sci 2014; 59: 2020-2022.

12. Esgalhado M, Stockler-Pinto MB, Ludmila FM, Cardozo CC, Barboza JE. Effect of acute intradialytic strength physical exercise on the oxidative stress and inflammatory responses in HD patients. Kidney Res Clin Pract 2015; 34: 35-40.

13. Seong EY. Acute intradialytic exercise and oxidative stress in hemodialysis patients. Kidney Res Clin Pract 2015; 34: $1-3$.

14. Heiwe S, Jacobson SH. Exercise training in adults with CKD: a systematic review and meta-analysis. Am J Kidney Dis 2014; 64: 383-393.

15. Mafra D, Fouque D. Lower physical activity and depression are associated with hospitalization and shorter survival in CKD. Clin J Am SocNephrol 2014; 9: 1669-1670.

16. Kimmel PL, Peterson RA. Depression in end-stage renal disease patients treated with hemodialysis: tools, correlates, outcomes, and needs. Seminars in Dialysis 2005; 18: 91-97.

17. Lopes AA, Bragg J, Young E, Goodkin D, Mapes D, Combe C. Depression as a predictor of mortality and hospitalization among hemodialysis patients in the United States and Europe. Kidney Int 2002; 62: 199-207.

18. Drayer RA, Piraino B, Reynolds CF, Houck PR, Mazumdar $\mathrm{S}$, Bernardini J. Characteristics of depression in hemodialysis patients: symptoms, quality of life and mortality risk. General Hospital Psychiatry 2006; 28: 306-312.

19. Levendoglu F, Altintepe L, Okudan N, Ugurlu H, Gokbel $\mathrm{H}$, Tonbul Z. A twelve week exercise program improves the psychological status, quality of life and work capacity in hemodialysis patients. J Nephrol 2004; 17: 826-832.

20. Millagerdi LJ, Mohamad Khan SK, Meamarian R. Assessment of regular exercise effect on hemodialysis children $8-12$ y old in children medicine of Tehran. Daneshvar J 2002; 40: 28-23.

21. Milani RV, Lavie CJ, Mehra MR, Ventura HO. Impact of exercise training and depression on survival in heart failure due to coronary heart disease. Am J Cardiol 2011; 107: 64-68.

22. Oeland AM, Laessoe U, Olesen AV, Munk-Jørgensen P. Impact of exercise on patients with depression and anxiety. Nordic J Psychiatry 2010; 64: 210-217.

23. Carmona Arcos M, Sánchez Castro AM, Peñarrocha Matarán GA, Rubio Gutiérrez AB, González Ramos E, Lorenzo Moreno C. Effects of aerobic exercise program and relaxation techniques on anxiety, quality of sleep, 
depression, and quality of life in patients with fibromyalgia: a randomized controlled trial. Medicina Clínica 2011; 137 : 398-401.

24. Ribeiro R, Coutinho GL, Iuras A, Barbosa AM, Souza JAC, Diniz DP. Effect of resistance exercise intradialytic in renal patients chronic in hemodialysis. Jornal Brasileiro de Nefrologia 2013; 35: 13-19.

25. Kirsten A, Bar T, Hennig JT, Kuchinke S, Krause R, Rost JM. A structured exercise programme during haemodialysis for patients with chronic kidney disease: clinical benefit and long-term adherence. BMJ Open 2015; 5.

26. Lee SJ, Jeon JH. A systematic review of effectiveness of exercise on QOL in patients with CKD. Healthcare and Nursing 2016; 128: 73-77.

27. Koeh M, Meerlo P, Gonzales D, Rontal A, Turek FW, Abrous DN. Exercise-induced promotion of hippocampal cell proliferation requires $\beta$-endorphin. FASEB J 2008; 22: 2253-2262.

28. Hegadoren KM, O'Donnell T, Lanius R, Coupland NJ, Masmonteil Lacaze $N$. The role of $\beta$-endorphin in the pathophysiology of major depression. Neuropeptides 2009; 43: 341-353.

29. Krogh J, Nordentoft M, Nezhad Mohammad M, Westrin A. Growth hormone, prolactin and cortisol response to exercise in patients with depression. J Affective Disorders 2010; 125: 189-197.

30. Mahrova A. Physical activity is a necessary part of care in patients with chronic kidney disease-short historical overview. Prim Health Care 2017; 7: 271.

\section{*Correspondence to}

Amirtha Santhi S

Saveetha University

Chennai

Tamil Nadu

India 